\title{
Comparative Study by Image Analysis of WC-Co Alloys Elaborated by Liquid Phase Sintering and Hot Isostatic Pressing
}

\author{
Hassiba Rabouhi ${ }^{1 *}$, Youcef Khelfaoui ${ }^{2}$, Abdelkrim Khireddine ${ }^{3}$ \\ ${ }^{1}$ Faculty of Exact Sciences, University of Bejaia, Road of Targa Ouzemmour, Bejaia 06000, Algeria \\ ${ }^{2}$ Mechanics, Materials \& Energy Laboratory (L2ME), Faculty of Technology, University of Bejaia, Bejaia 06000, Algeria \\ ${ }^{3}$ Faculty of Technology, University of Bejaia, Road of Targa Ouzemmour, Bejaia 06000, Algeria
}

Corresponding Author Email: hassiba.rabouhi@univ-bejaia.dz

https://doi.org/10.18280/acsm.440405

Received: 10 May 2020

Accepted: 21 July 2020

\section{Keywords:}

sintering, hot isostatic pressing-cemented carbide, hardness, microstructure, image analysis

\begin{abstract}
Hot isostatic pressing (HIP) is known to be a process which permits to elaborate totally dense cemented carbide with perfect homogenous structure. It also offers the possibility to totally consolidate the powders mixtures WC-Co without reaching the fusion temperature of the binding cobalt. The HIP process was used in this work to produce a cemented carbide with an 8,11 and $20 \%$ cobalt mass. Their properties are thus compared with those of similar samples elaborate by liquid phase sintering. The microstructural characterization of both types of samples is described from observation by scanning electron. The qualitative analysis of the sample is realized by X-ray diffraction and energy dispersion. The use of image analysis techniques allowed us to access the morphological parameters of the binding phase in both types of elaborate sample. The spectra obtained by $\mathrm{X}$-ray diffraction show, the absence of the phase $\left(\mathrm{Co}_{3} \mathrm{~W}_{3} \mathrm{C}, \mathrm{Co}_{6} \mathrm{~W}_{6} \mathrm{C}\right)$ for the sample elaborated by hot isostatic pressing (HIP) method, unlike sintering in the liquid phase where it is clearly highlighted. The SEM observations clearly show the absence of residual carbon inclusions for the HIP method as well as the best distribution of the phases highlighted by the images obtained by mapping. In conclusion, the results obtained give us a clear idea on improving densification, increasing hardness and decreasing porosity for the HIP hot isostatic pressing method.
\end{abstract}

\section{INTRODUCTION}

The techniques of powder metallurgy are used in the context of this work to elaborate cemented carbides based on powders of tungsten carbide and cobalt mixed in previously selected proportions by mass. Conventional sintering with cobalt liquid phase formation remains the most often used process $[1,2]$. However, the products obtained are not always very dense and have two types of heterogeneities, that of $\mathrm{WC}$ and $\mathrm{Co}$ components and that of residual porosities [3]. A recrystallization of the structure due to the growth of the grain by dissolution precipitation can also be observed in this type of material. Recrystallization the presence of carbon and porosities can cause limitation and dispersion of the mechanical characteristics of the products thus obtained [4].To remedy these insufficiencies, the sintering cycle is generally terminated by increasing the gas pressure (up to $10 \mathrm{MPa}$ ) for a certain time in order to eliminate the residual porosity and improve the homogeneity of the final product. This operation proves to be insufficient especially in the case of cemented carbides with low cobalt content (containing less than $10 \%$ by weight of Co).As part of this work, we searched to optimize the mechanical properties of cemented carbides by densifying WC-Co mixtures by hot isostatic pressing (H.I.P) [5-7]. Indeed, the HIP is known to be a process that allows to elaborate composite materials with perfectly homogeneous structures [8]. The focus of the analysis is on the changes in microstructures and the mechanical properties caused by hot isostatic pressing HIP [9]. The idea of going towards the use of the HIP method consists in improving the densification and the microstructure and mechanical properties of these materials [10]. Therefore, the decrease in porosity which will lead to the improvement of the mechanical properties of the material produced [11].

As part of this work, two types of tungsten carbides containing 8,11 and $20 \%$ by weight of cobalt were elaborated by hot isostatic pressing, their properties are compared with those of samples elaborated by liquid phase sintering.

\section{EXPERIMENTAL METHOD}

The preparation of the base powders of the carbides elaborated is realized in the laboratory of the ERIS industrial unit of Batna (Algeria). In a first step, we proceed to the reduction by hydrogen from tungsten trioxide and cobalt dioxide to obtain $\mathrm{W}$ and Co. powders. We then proceed to carburizing $\mathrm{W}$ powders using carbon black to obtain a WC powder whose mass percentage of carbon must be very close to $5 \%$. The mass of carbon black entering in reaction with tungsten is given by the following empirical relation:

$$
Q_{c}=\left[\frac{C}{100-C} K+\frac{0.75 O_{2}}{100}\right] Q_{W} \frac{1}{X}
$$

where, 
$\mathrm{Q}_{\mathrm{c}}$ is the mass of carbon black in $\mathrm{kg}$;

$\mathrm{Q}_{\mathrm{W}}$ is the mass of tungsten in $\mathrm{kg}$;

$\mathrm{C}$ is the percentage of carbon used for carburization;

$\mathrm{O}_{2}$ is the percentage of $\mathrm{O}_{2}$ existing in the $\mathrm{WC}$;

$\mathrm{K}$ is the carburization coefficient;

$\mathrm{X}$ is the percentage of graphite purity.

The mixture of the powders of $\mathrm{WC}$ and $\mathrm{Co}$, in proportions previously chosen, is realized by wet grinding to optimize its homogenization. The product obtained is dried to obtain a mixture of two-component powders $\mathrm{WC}$ and $\mathrm{Co}$ which will be used to elaborate the WC-Co composites. The WC and Co powders used are of a polydisperse nature. The grain sizes of WC and Co powders are respectively less than 5 and $2 \mu \mathrm{m}$.

The chemical compositions of the powder mixtures obtained are shown in Table 1.

Two types of cemented carbides were prepared from three mixtures of WC and Co powders containing 8.11 and $20 \%$ by weight of cobalt. Three samples of these mixtures were obtained by liquid phase sintering and three others of the same compositions are densified by hot isostatic pressing

The sintering of the three powder mixtures is realized under a hydrogen atmosphere in three stages.

In a first stage, the mixture is carried to a temperature of $800^{\circ} \mathrm{C}$ for four hours to remove the binder used for shaping the samples by uni-axial compression cold.

During the second step, the temperature is gradually increased from $800^{\circ} \mathrm{C}$ to $1450^{\circ} \mathrm{C}$ for two hours to bind the WC grains by the Co in fusion. This stage lasting two hours generates a progressive enrichment of cobalt in carbon from $1280^{\circ} \mathrm{C}$ according to the WC-Co equilibrium diagram [5].

Mixtures of powders to be treated by hot isostatic pressing are poured and then tamped by vibration in containers with titanium cap and cylindrical shape. densification is realized in the containers previously sealed under vacuum by electron bombardment.

Table 1. Composition of basic powder mixtures

\begin{tabular}{ccc}
\hline Sample & \multicolumn{2}{c}{ \% by mass of elements } \\
\hline & Carbon & Cobalt \\
\hline WC-8\%Co & 5.3 & 7.9 \\
WC-11\%Co & 5.1 & 11.2 \\
WC-20\%Co & 4.9 & 20.1 \\
\hline
\end{tabular}

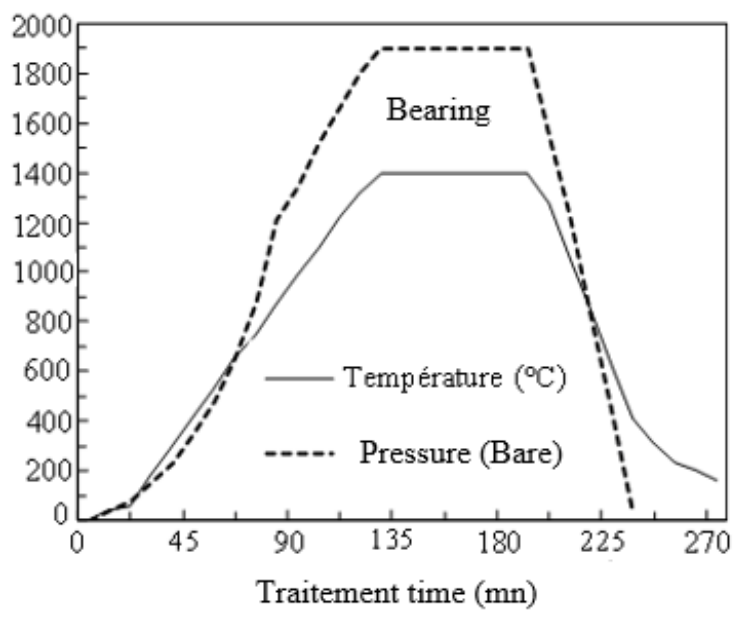

Figure 1. Hot isostatic pressing treatment cycle
The HIP tests are realized using a HIP 6 type press of the physical metallurgy laboratory of Poitiers (France). The operation of the press is governed by macro-commands that start automatic sequences whose progress is controlled by a programmable automaton. The course of the HIP processing cycle is governed by pressure and temperature programs previously loaded into two programmable automatons. A cycle is a set of stages where the variation of pressure or temperature is rigorously controlled. These steps may constitute mounts, bearing or descents. The hot isostatic pressing treatment cycle used to elaborate the two cemented carbides studied is represented by the graphs of Figure 1.

\section{EXPERIMENTAL RESULTS AND DISCUSSION}

The X-ray diffraction analysis is realized using an XRG 3000 diffractometer with a voltage of $30 \mathrm{KV}$. The wavelength used is the chromium $\mathrm{K}_{\alpha}$ line. The characteristics spectrums of the two types of samples are shown in Figures 2 and 3. We note the existence of the $\eta\left(\mathrm{Co}_{3} \mathrm{~W}_{3} \mathrm{C}, \mathrm{Co}_{6} \mathrm{~W}_{6} \mathrm{C}\right)$ phase in the samples obtained by liquid-phase sintering which are practically not found in those prepared by hot isostatic pressing. The dissolution-precipitation mechanism is probably at the origin of the appearance of the $\eta$ phase in samples prepared by conventional sintering. The long duration of liquid phase sintering treatment favors this phenomenon. The WC grains dissolve and the released $\mathrm{W}$ and carbon atoms diffuse through the liquid phase and react with the cobalt to form the $\eta$ phase during cooling. An excess of carbon gives rise to graphite precipitates and a defect of it generates carbides mixed under stoichiometric carbon $\left(\mathrm{Co}_{3} \mathrm{~W}_{3} \mathrm{C}, \mathrm{Co}_{6} \mathrm{~W}_{6} \mathrm{C}\right)[12$, 13].

Scanning electron microscopy observations, carried out in backscattered electron mode, provided information on the phases in the two types of elaborate samples. Their surfaces were prepared by mechanical polishing successive to the diamond paste of 10 to $0.25 \mu \mathrm{m}$. For more details on selected cemented carbide and cermet microstructures, a review is presented in reference [14]. The micrograph of Figure 4 represents the appearance of the structure observed in the samples elaborated by H.I.P. The electron microscope observations revealed a structure different from that observed in the alloys obtained by liquid phase sintering (Figure 5). It is characterized by a closed cobalt phase especially in the case of alloys with a low cobalt content ( 8 and $11 \%$ by weight of cobalt) where the binder appears finely dispersed in the form of small particles. As for the tungsten carbide phase, it is in the form of a phase consisting of grains difficult to distinguish.

Microscopic observations revealed a very small volume fraction of residual carbon inclusions in the samples obtained by liquid phase sintering. On the other hand, no inclusion of this type is observed in the samples elaborated by hot isostatic pressing. The high pressure applied at $1420^{\circ} \mathrm{C}$ is probably responsible for the dissolution of residual graphite in cobalt in the liquid phase.

Energy dispersion analysis is realized in a complementary manner on the agglomerated cluster areas and the inclusions observed in the samples produced by liquid phase sintering. The results obtained are presented in Figure 6 and 7 in the form of maps that highlight the geographical distribution of the carbon, tungsten and cobalt elements. 


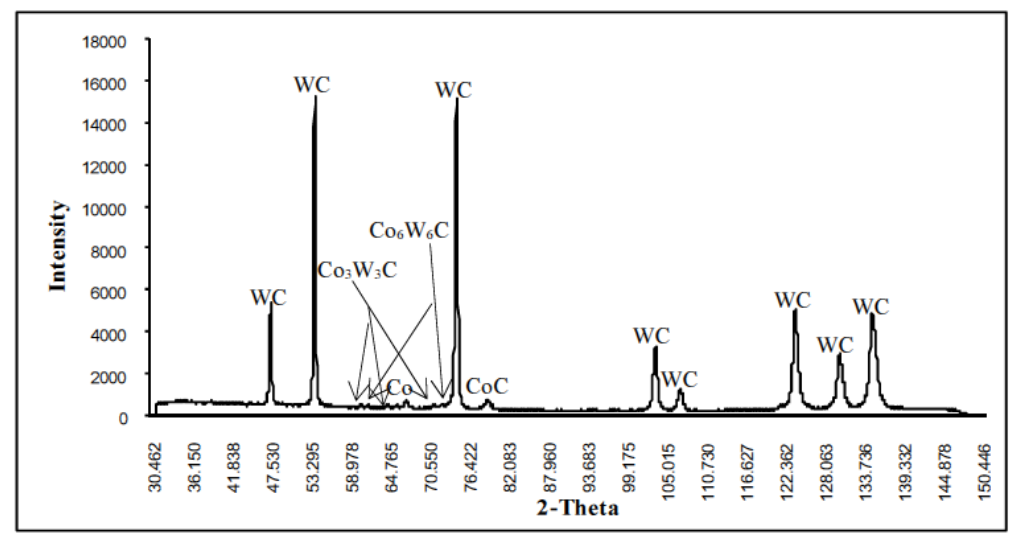

Figure 2. X-ray diffraction spectrum of WC- $8 \%$ Co sample sintered at $1420^{\circ} \mathrm{C}$

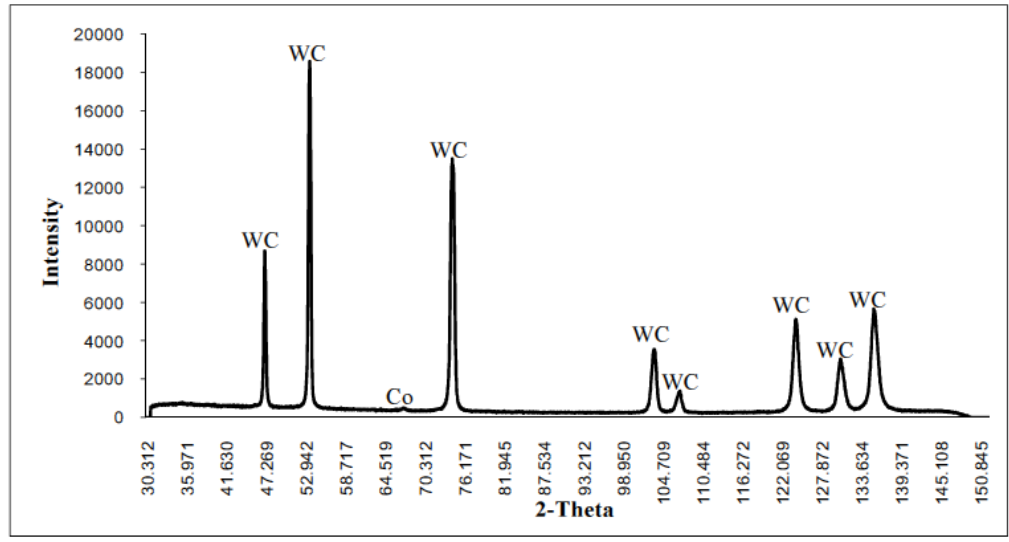

Figure 3. X-ray diffraction spectrum of WC- $8 \%$ Co mixtures elaborated by H.I.P at $1420^{\circ} \mathrm{C}$

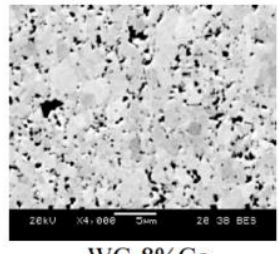

WC- $8 \%$ Co

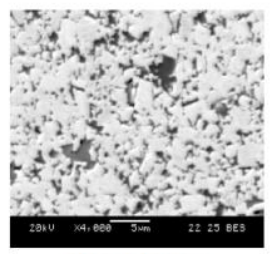

WC- $11 \% \mathrm{Co}$

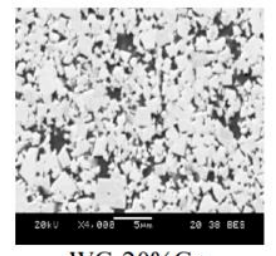

WC- $20 \% \mathrm{Co}$
Figure 4. Microstructures observed in samples obtained by $\mathrm{HIP}$ at $1420^{\circ} \mathrm{C}$

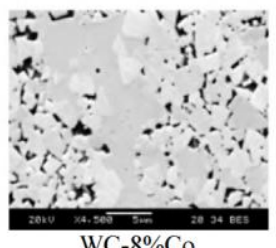

$\mathrm{WC}-8 \% \mathrm{Co}$

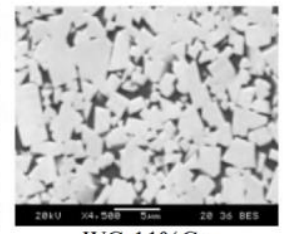

WC- $11 \% \mathrm{Co}$

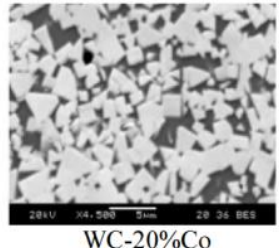

WC- $20 \% \mathrm{Co}$

Figure 5. Microstructures observed in samples obtained by liquid phase sintering at $1420^{\circ} \mathrm{C}$

The mapping of Figure 6 clearly shows that the inclusions contained in the alloys obtained by sintering consist essentially of carbon. They may correspond to the residual graphite

remaining after the carburizing step or to the carbon which forms by precipitation during the duration of the sintering operation.

Concerning grain clusters, the analysis carried out shows that they consist of tungsten, cobalt and carbon as shown in the maps in Figure 7.This phenomenon suggests that, during the sintering process, the carbon balance is not ensured since it leads to the formation of the $\eta$ phase in the form of compounds $\mathrm{Co}_{3} \mathrm{~W}_{3} \mathrm{C}$ or $\mathrm{Co}_{6} \mathrm{~W}_{6} \mathrm{C}$.

A comparative study by image analysis was realized on the samples elaborated by H.I.P and by simple sintering. The images of the transverse sections of the samples studied, once digitized, are thresholder in order to obtain binary images. The morphology function is composed of operators which are the opening and the closing which serve to eliminate the imperfections observed on the binary images. The open binary image obtained is then reversed. The measurements made permit to obtain morphological characteristics of the binder particles.

To improve the statistical value of the results, five different ranges are analyzed every time. The experimental values retained are averages calculated from the values thus obtained.

Hadwiger [15] shows that in a space of order $n$, the stereological parameters are $\mathrm{n}+1$, of which $\mathrm{n}$ are metric parameters and one topological parameter. 


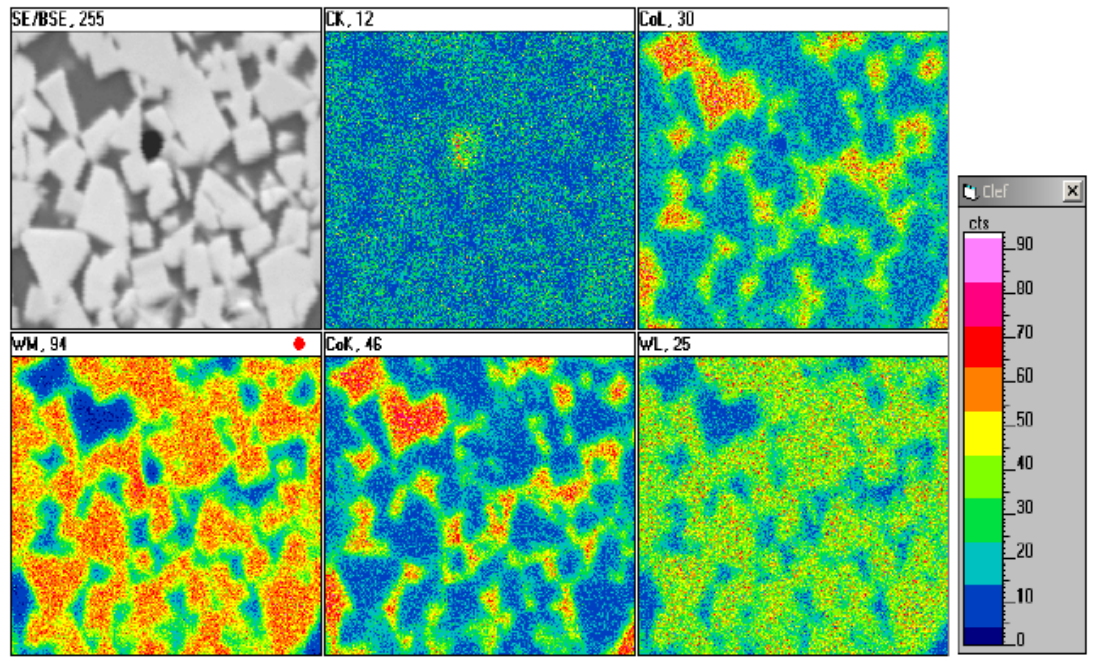

Figure 6. Cartography of the WC-20\% Co sample elaborated by liquid phase sintering containing an inclusion of carbon
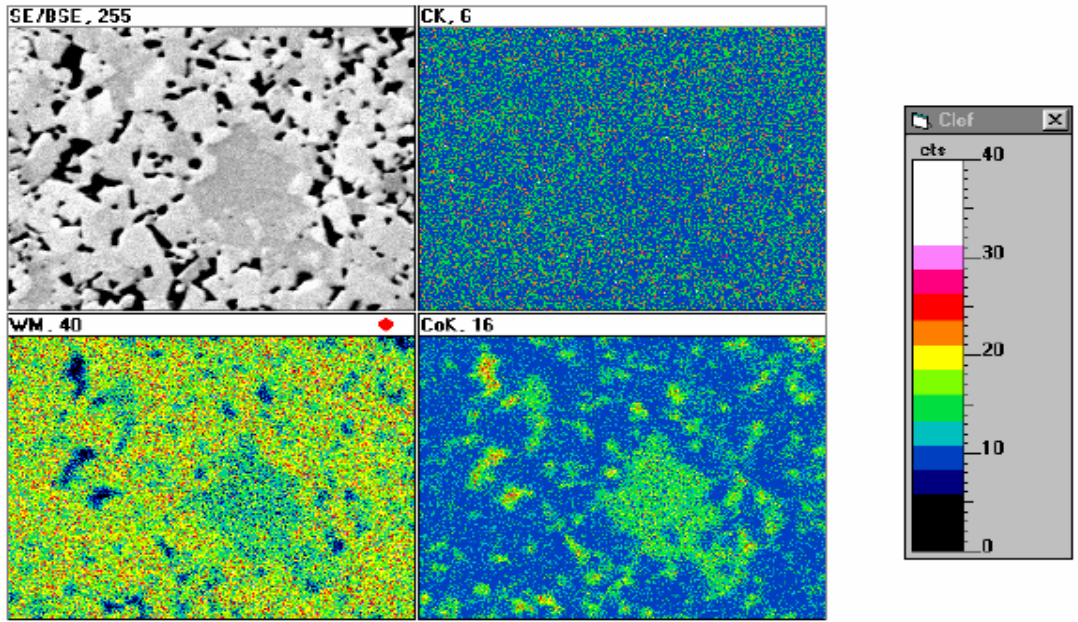

Figure 7. Cartography of elements $\mathrm{C}, \mathrm{W}$ and $\mathrm{Co}$ in the sample containing $8 \%$ by mass Cobalt obtained by conventional sintering

These are stereological parameters that make it possible to characterize:

- $\quad$ the binding phase of the carbide $\mathrm{WC}-\mathrm{Co}$

- the hard phase of WC

- $\quad$ the separation surface between the hard phase and the binder phase.

- the volume fractions and the specific surface area are basic parameters.

The volume fractions $\mathrm{V}_{\mathrm{V}}$ (WC) and $\mathrm{V}_{\mathrm{V}}$ (Co) are complementary if the material is totally dense. In the opposite case, the volume fraction $\mathrm{V}_{\mathrm{V}}(\mathrm{P})$ of the residual porosity must be taken into account. We then write:

$$
V_{V}(W C)+V_{V}(C o)+V_{V}(P)=1
$$

The $S_{V}$ specific surface area corresponds to the area of the separation surface between the hard phase and the binder phase per unit volume of the material. The number of connectivity per unit length $\mathrm{N}_{\mathrm{L}}$, makes it possible to calculate it:

$$
\mathrm{S}_{\mathrm{V}}=4 \mathrm{~N}_{\mathrm{L}}
$$

The average free path in both $\mathrm{WC}$ and Co phases is a secondary parameter that is given by:

$$
\bar{L}(X)=\frac{4 V_{V}(X)}{S_{V}(X)}
$$

where, $\mathrm{X}$ represents the hard phase WC where the binding phase Co.

The volume fraction $\mathrm{V}_{\mathrm{V}}(\mathrm{L})$ of the binding phase corresponds to the specific number of connectivity in the space $\mathrm{R}^{0}$ obtained automatically on the inverse binary images of the sections of the two types of samples whose aspects are represented in Figures 8 and 9.

The morphological parameters defined by the specific surface area $\mathrm{S}_{\mathrm{v}}(\mathrm{Co} / \mathrm{WC})$ and the average free path $\overline{\mathrm{L}}_{\mathrm{L}}$ in the binder phase were calculated using the relationships mentioned above. The results obtained are grouped in Tables 2 and 3. The evolution of these parameters as a function of the cobalt content is described by the curves of Figures 10 and 11 .

Table 2. Morphological characteristics of the binder phase in WC-Co samples elaborated by liquid phase sintering

\begin{tabular}{cccc}
\hline Samples & $\begin{array}{c}\text { Percentage } \\
\text { mass in Co }(\%)\end{array}$ & $\mathbf{S}_{\mathbf{v}}(\boldsymbol{\mu m})^{-\mathbf{1}}$ & $\overline{\mathrm{L}}(\boldsymbol{\mu m})$ \\
\hline WC-8\%Co & 8 & 1.0211 & 0.4163 \\
WC-11\%Co & 11 & 1.0150 & 0.4828 \\
WC-20\%Co & 20 & 1.2908 & 0.7950 \\
\hline
\end{tabular}


Table 3. Morphological characteristics of the binder phase in WC-Co samples elaborated by H.I.P

\begin{tabular}{cccc}
\hline Samples & $\begin{array}{c}\text { Percentage } \\
\text { mass in Co }(\%)\end{array}$ & $\mathbf{S}_{\mathbf{v}}(\boldsymbol{\mu m})^{-1}$ & $\overline{\mathrm{L}}(\boldsymbol{\mu m})$ \\
\hline WC-8\%Co & 8 & 0.9871 & 0.3321 \\
WC-11\%Co & 11 & 1.0063 & 0.4512 \\
WC-20\%Co & 20 & 1.8345 & 0.4335 \\
\hline
\end{tabular}

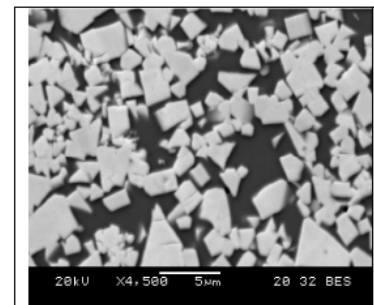

(a)

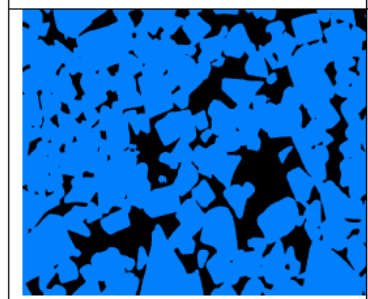

(c)

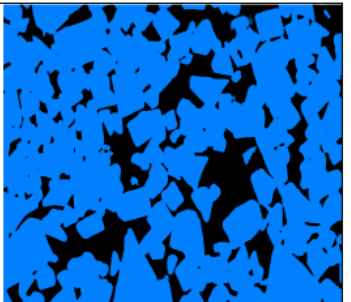

(b)

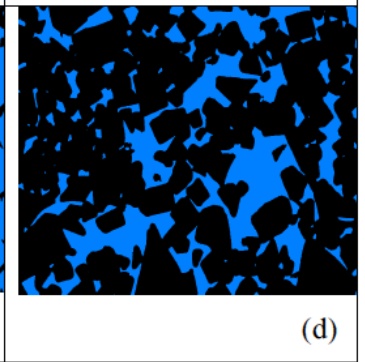

a) Image at 256 levels of gray b) Binary image c) Open binary image d) Open inverse binary image

Figure 8. Observation of a transverse section of the WC-20\% Co sample elaborated by liquid phase sintering

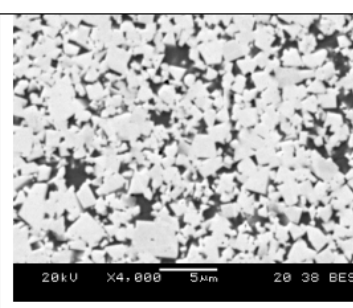

(a)

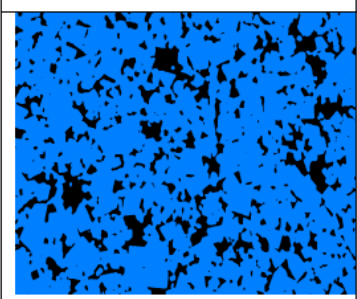

(c)

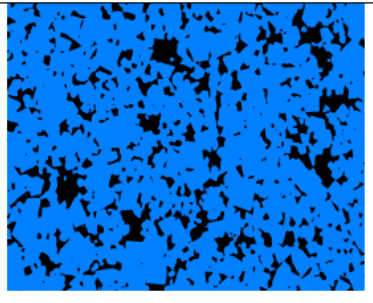

(b)

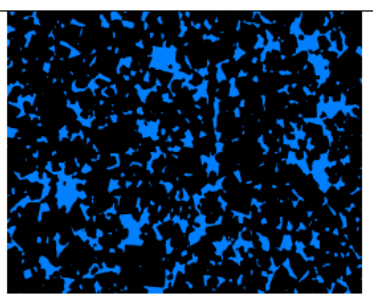

(d) a) Image at 256 levels of gray b) Binary image c) Open binary image d) Open inverse binary image

Figure 9. Observation of WC-20\% Co sample elaborated by H.I.P

The Figure 10 shows that the specific surface area is essentially the same in both types of samples when the cobalt content is 8 or $11 \%$. It increases rapidly when the mass fraction of cobalt is $20 \%$. We note that this increase is much larger in the case of samples obtained by H.I.P. This result suggests that the densification process used involves mechanisms that lead to a reduction of the binder phase clusters into much smaller particles that tend to take spheroidal forms.
The average free path in the binder phase changes little in the field of low cobalt contents in both types of samples elaborated. In the case of high contents, it is found that it increases strongly in the samples elaborated by conventional sintering but remains practically constant in the compressed obtained by H.I.P (Figure 11).

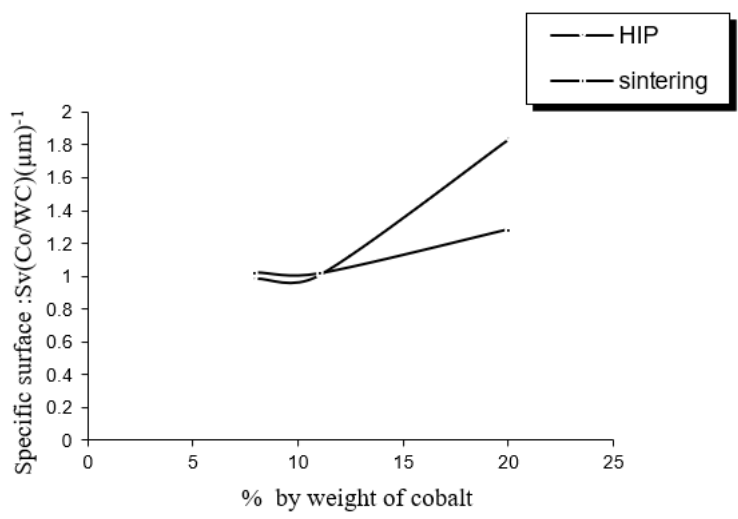

Figure 10. Evolution of the specific surface according to the cobalt content

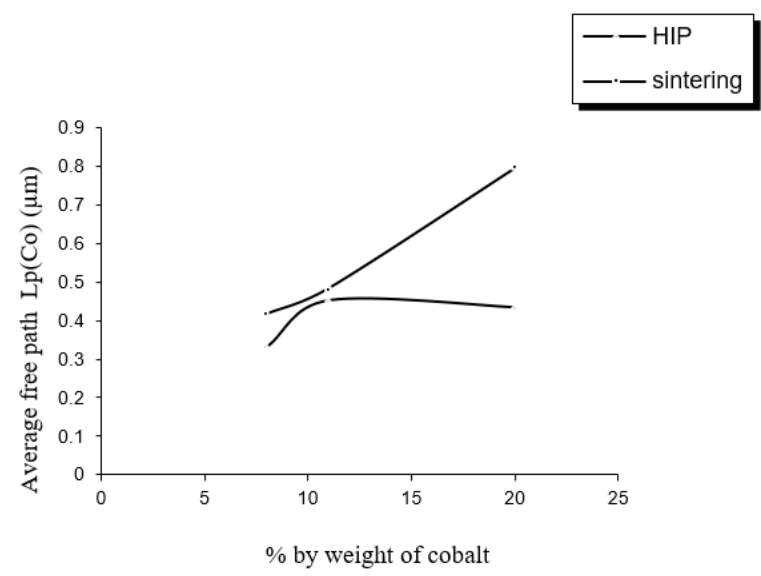

Figure 11. Evolution of the average free path in the binding phase

Micro-hardness tests were realized on both types of samples elaborated by liquid phase sintering and hot isostatic pressing. The tests were performed using a load of 500grs applied for $15 \mathrm{~s}$.

The average hardness was evaluated from about ten points along the right segment that connects the edge to the center of the sample. All the results relating to the tests realized are presented in Table 4.

Table 4. Micro-hardness of both types of elaborate alloys

\begin{tabular}{ccc}
\hline Sample & $\begin{array}{c}\text { liquid phase } \\
\text { sintering at } 1420^{\circ} \mathbf{C}\end{array}$ & $\begin{array}{c}\text { H.I.P at } \\
\mathbf{1 4 2 0}^{\circ} \mathbf{C}\end{array}$ \\
\hline WC-8\%Co & $1522 \pm 28.15$ & $1667 \pm 26.53$ \\
WC-11\%Co & $1294 \pm 31.18$ & $1426 \pm 23.5$ \\
WC-20\%Co & $1042 \pm 65.20$ & $1201 \pm 31.96$ \\
\hline
\end{tabular}

The results obtained show that the H.I.P densification process permit to obtain WC-Co carbides with improved mechanical properties. The improvement of the microhardness is certainly due to the morphology of the binder phase which is in a dispersed form in the samples elaborated by hot isostatic pressing. 


\section{CONCLUSIONS}

Liquid phase sintering is used to elaborate WC-Co carbide carbides that combine the hardness of carbide with the toughness provided by the cobalt binder. However, the quality of the shade to be produced depends largely on the care with which the mixing of the two powders is realized. The products obtained by liquid phase sintering are even more homogeneous as the mixture of base powders approaches the ideality. We sought to optimize the homogeneity of cemented carbides by densification of basic mixtures by hot isostatic pressing. This process is used in the context of this work to manufacture WC-Co cemented carbides totally dense and with performance mechanical properties.

X-ray diffraction analysis has shown that densification by H.I.P does not cause decarburization of the WC grains. Indeed, the diffraction spectrums obtained on the samples elaborated by H.I.P include only the cobalt and tungsten carbide lines. On the other hand, rays of the $\eta$ and $\mathrm{CoC}_{x}$ phase appear clearly on the X-ray diffraction spectrum corresponding to the samples obtained by sintering.

The Observations made with a scanning electron microscope have shown that the samples elaborated by H.I.P are more homogeneous than those obtained by sintering. In fact, there is the presence of particle clusters and inclusions of graphite in the sintered samples. The graphite is probably generated by the decarburization which takes place during the sintering step with liquid phase. The energy dispersion analysis of these zones has also revealed that a significant fraction of cobalt diffuses into the WC grains during the hot isostatic pressing.

The study by image analysis realized on the two types of alloys elaborated by H.I.P and by liquid phase sintering permit to determine then to compare the main morphological characteristics of the binding phase of the two types of elaborated carbides. It is found that the specific surface of the WC-Co interface is much larger in the samples elaborated by H.I.P. his result shows that this powerful process involves mechanisms that allow a very homogeneous distribution of the binder phase in the form of small particles finely dispersed in the case of low cobalt contents. Concerning the average free path, it increases strongly with the increase of the cobalt content in the samples elaborated by conventional sintering but varies little in the case of the compressed elaborated by H.I.P. The heterogeneity of the binder phase in the samples obtained by sintering is therefore all the more accentuated as the cobalt content is high.

The determination of the mechanical properties was carried out from micro-hardness tests. It is found that the microhardness is significantly higher in the samples elaborated by hot isostatic pressing. The improvement of the micro-hardness is certainly due to the homogeneity of the distribution of the binder phase in the samples treated by hot isostatic pressing [4].

In conclusion, we can say that the H.I.P process generates a better homogenization of the binder phase by causing the elimination of residual clusters of cobalt and carbide which remain after the mixing of the base powders.

\section{REFERENCES}

[1] German, R.M. (1985). Liquid Phase Sintering. Plenum Press, New York.

[2] Chaix, J.M. (1993). Le Frittage en Phase Liquide, in Chimie Physique du FRIttage. Hermès: Paris, 251-283.

[3] Bernache-Assolant, D. (1993). Chimie Physique du Frittage. Hermes Science Publications, Paris.

[4] Bichaud, E. (2016). Frittage "flash" de céramiques sous courant alternatif. Thesis. Génie des Procédés, Université Grenoble Alpes, France, NNT: 2016GREAI028. https://tel.archives-ouvertes.fr/tel-01483723/document, accessed on 20 July, 2020.

[5] Rabouhi, H., Boudrahem, S., Grosbras, M. (2007). Etude comparée des propriétés de carbures cémentés élaborés par frittage et compression isostatique à chaud. Annales de Chimie Science des Matériaux, 32(1): 11-18. https://doi.org/10.3166/acsm.32.11-18

[6] Di, L.M., Calka, A., Li, Z.L., Williams, J.S. (1995). The formation of ternary compound $\mathrm{Fe}_{3} \mathrm{Mo}_{3} \mathrm{C}$ by ball milling. Journal of Applied Physics, 78(6): 4118. https://doi.org/10.1063/1.360705

[7] Benjamin, J.S., Volin, T.E. (1974). The mechanism of mechanical alloying. Metallurgical Transactions, 5: 1929-1934. https://doi.org/10.1007/BF02644161

[8] Upadhyaya, G.S. (2001). Materials science of cemented carbides-an overview. Materials \& Design, 22(6): 483489. https://doi.org/10.1016/S0261-3069(01)00007-3

[9] Kunz, J., Boontanom, A., Herzog, S., Suwanpinij, P., Kaletsch, A., Broeckmannac, C. (2020). Influence of hot isostatic pressing post-treatment on the microstructure and mechanical behavior of standard and super duplex stainless steel produced by laser powder bed fusion. Materials Science and Engineering: A, 794: 139806. https://doi.org/10.1016/j.msea.2020.139806

[10] Dong, D., Xiang, X., Huang, B., Xiong, H., Zhang, L., Shi, K., Liao, J. (2020). Microstructure and properties of WC-Co/CrMnFeCoNi composite cemented carbides. Vacuum, 179 : 109571. https://doi.org/10.1016/j.vacuum.2020.109571

[11] Rabouhi, H., Boudrahem, S., Khireddine, A. (2016). Characterization of cemented carbide containing $11 \%$ mass cobalt elaborated by hot isostatic pressing: A study of the reactivity of the steel container with the component WC. Ann. Chim. Sci. Mat., 40(3-4): 111-120. https://doi.org/10.3166/acsm.40.111-120

[12] Exner, H.E. (1979). Physical and chemical nature of cemented carbides. International Metals Reviews, 24: 149-173. https://doi.org/10.1179/imtr.1979.24.1.149

[13] Pollock, C.B., Stadelmaier, H.H. (1970). The eta carbides in the $\mathrm{Fe}-\mathrm{W}-\mathrm{C}$ and $\mathrm{Co}-\mathrm{W}-\mathrm{C}$ systems. Metallurgical Transactions, 1: 767-770. https://doi.org/10.1007/BF02811752

[14] García, J., Collado Ciprés, V., Blomqvist, A., Kaplan, B. (2019). Cemented carbide microstructures: A review. International Journal of Refractory Metals and Hard Materials, 80: 40-68. https://doi.org/10.1016/j.ijrmhm.2018.12.004

[15] Hadwiger, H. (1957). Vorsungen Über Inhalt, Oberfläche und Isopérimétrie, Springer. Verlag, Berlin. https://doi.org/10.1007/978-3-642-94702-5

\section{NOMENCLATURE}

$Q_{c}$

$\mathrm{Q}_{\mathrm{w}}$

C mass of carbon black in $\mathrm{kg}$ mass of tungsten in $\mathrm{kg}$ percentage of carbon 
$\mathrm{O}_{2} \quad$ percentage of $\mathrm{O}_{2}$

$\mathrm{K} \quad$ carburization coefficient

$\mathrm{X}$

$\mathrm{V}_{\mathrm{v}}(\mathrm{X})$

$\mathrm{V}_{\mathrm{v}}(\mathrm{WC})$

$\mathrm{V}_{\mathrm{v}}(\mathrm{Co})$

$\mathrm{V}_{\mathrm{v}}(\mathrm{p})$

$\mathrm{S}_{\mathrm{V}}$ percentage of graphite purity

volume fraction of the hard phase where the

Co binding phase

volume fraction of $\mathrm{WC}$

volume fraction of $\mathrm{Co}$

volume fraction of the residual porosity

specific surface area per unit volume
$\mathrm{N}_{\mathrm{L}} \quad$ number of connectivity per unit length

$\bar{L}(X) \quad$ average free path in both $\mathrm{WC}$ and Co phases $(\mu \mathrm{m})^{-1}$

$\mathrm{V}_{\mathrm{v}}(\mathrm{L}) \quad$ volume fraction of binding phase

\section{Greek symbols}

$\eta \quad$ phase neta

$\mathrm{K}_{\alpha} \quad$ Chromium line 